\title{
Sinorhizobium medicae sp. nov., Isolated from Annual Medicago spp.
}

\author{
SOPHIE ROME, ${ }^{1,2 *}$ MARIA P. FERNANDEZ, ${ }^{2}$ BRIGITTE BRUNEL, ${ }^{1,3}$ PHILIPPE NORMAND, ${ }^{2}$ AND \\ JEAN-CLAUDE CLEYET-MAREL ${ }^{1}$
}

\author{
Laboratoire de Recherche sur les Symbiotes des Racines, I.N.R.A-E.N.S.A.M., ${ }^{1}$ and Unité de Formation et de \\ Recherche de Science du Sol, 34060 Montpellier cedex 01, and Laboratoire d'Ecologie Microbienne \\ du sol UMR CNRS 5557, Université Lyon I, 69622 Villeurbanne cedex, ${ }^{2}$ France
}

\begin{abstract}
The taxonomic position of isolates of a new genomic species (designated genomic species 2) obtained from several annual Medicago species and originating from different geographical locations was established through the results of phenotypic tests (including the results of auxanographic and biochemical tests and symbiotic properties) and $16 \mathrm{~S}$ rRNA phylogenetic inferences. A comparison of the complete $16 \mathrm{~S}$ rRNA sequence of a representative of genomic species 2 (strain $A 321^{T}$ [ $T=$ type strain]) with the 16S rRNA sequences of other members of the Rhizobiaceae and closely related taxa showed that genomic species 2 was phylogenetically related to Sinorhizobium meliloti, Sinorhizobium fredii, Sinorhizobium saheli, and Sinorhizobium teranga. The levels of sequence similarity and observed numbers of nucleotide substitutions in Sinorhizobium strains indicated that $\mathrm{A} 321^{\mathrm{T}}$ and $S$. meliloti exhibited the highest level of sequence similarity $(99.7 \%$ ), with four nucleotide substitutions and one deletion. The results of a numerical analysis based on data from 63 auxanographic and biochemical tests clearly separated genomic species 2 isolates from S. meliloti. Genomic species 2 isolates nodulated and fixed nitrogen with Medicago polymorpha, whereas $S$. meliloti isolates were ineffective and formed rudimentary nodules on this host plant. On the basis of phenotypic and 16S sequence analysis data, genomic species 2 isolates cannot be assigned to a previously described species. We propose that these isolates belong to a new species, Sinorhizobium medicae.
\end{abstract}

The genera Rhizobium, Bradyrhizobium, Azorhizobium, and Sinorhizobium consist of soil bacteria that are capable of forming nitrogen-fixing nodules on leguminous plants (and on members of the nonlegume genus Parasponia). The genus $\mathrm{Si}$ norhizobium was first created for the fast-growing noduleforming soybean isolates which previously had been included in Rhizobium fredii (4). The low levels of similarity of this species with the other Rhizobium spp., as deduced from numerical taxonomy analyses, led to the proposal of the new genus (4). However, when a partial 16S rRNA sequence analysis was performed, Rhizobium meliloti and $R$. fredii were found to be close neighbors since they have identical partial $16 \mathrm{~S}$ sequences, and Jarvis et al. (15) suggested that these organisms should be reclassified in the genus Rhizobium.

More recently, new isolates obtained from Sesbania and Acacia species were found to constitute two new species belonging to the $R$. fredii- $R$. meliloti taxonomic group (5). In this study, which was based on phenotypic criteria, DNA-DNA and DNA-rRNA hybridization results, and 16S rRNA sequence comparisons, the authors found high levels of divergence between this group and the other Rhizobium species, which led them to place four species in the genus Sinorhizobium and to present an emended genus description. The emended genus Sinorhizobium contains four species, Sinorhizobium meliloti, Sinorhizobium fredii, Sinorhizobium teranga, and Sinorhizobium saheli, and $S$. fredii is the type species. This genus is now well-described, but the status of some species needs further refinement. In this paper, we present a revision of the species S. meliloti.

S. meliloti is classically described as an organism which forms

\footnotetext{
* Corresponding author. Mailing address: Laboratoire d'Ecologie Microbienne du Sol UMR CNRS 5557, Université Lyon I, Bâtiment 741, 43 Bd. du 11 Novembre 1918, 69622 Villeurbanne cedex, France. Fax: 72-43-12-23. Electronic mail address: sr@geometrie.univ-lyon1.fr.
}

symbiotic relationships with members of three genera of legumes, the genera Medicago, Melilotus, and Trigonella (10). Since the perennial species Medicago sativa is the most widely cultivated species of lucerne in the world, symbiotic strains obtained from this legume have been studied intensively and are included in many genetic and taxonomic studies of the Rhizobiaceae. In contrast, the taxonomy of sinorhizobia obtained from annual Medicago species is less well understood. Cross-inoculation data have shown that annual Medicago species exhibit various degrees of specificity in their symbioses $(2$, 3, 21); the most promiscuous plant species (e.g., Medicago minima, Medicago rigidula, and Medicago truncatula) fix nitrogen with most annual Medicago-infective isolates, while other Medicago species (e.g., Medicago laciniata, Medicago polymorpha, Medicago sauvagei, and Medicago rugosa) are more specific and form effective symbioses with only a few isolates. These findings suggest that there is a subspecific sinorhizobial structure. A multilocus electrophoresis and restriction fragment length polymorphism (RFLP) analysis of the 16S rRNA gene yielded two genetically distinct divisions, divisions $\mathrm{A}$ and B, for isolates obtained from various Medicago species (7), which supported the hypothesis that the species should be divided. In a previous study in which the genetic diversity of sinorhizobia that nodulate spontaneous annual Medicago species in the south of France was examined, $73 \mathrm{M}$. truncatulainfective sinorhizobia were characterized by using the DNA polymorphism of four amplified DNA regions localized on the symbiotic plasmid or on the chromosome. These isolates fell into two genotypic groups (22). DNA-DNA hybridization data showed that these groups represented two different genomic species (22). The first species corresponded to $S$. meliloti, whereas the members of the second group exhibited low levels of DNA homology with several $S$. meliloti strains and belonged to another genomic species. These results corroborated those of Eardly et al. (7), which strongly suggested that rhizobia that 
TABLE 1. Sinorhizobium strains used in this study

\begin{tabular}{|c|c|c|c|c|c|}
\hline Strain & Species $^{a}$ & $\begin{array}{l}\text { PCR-RFLP } \\
\text { group }^{a}\end{array}$ & Host plant & Geographical origin & Reference(s) \\
\hline A 17 & S. meliloti & 1 & Medicago truncatula & France (Aude) & 22 \\
\hline A $110 B$ & S. meliloti & 1 & Medicago truncatula & France (Aude) & 22 \\
\hline $\mathrm{V} 11 \mathrm{~A}$ & $S$. meliloti & 1 & Medicago truncatula & France (Var) & 22 \\
\hline V 127B & S. meliloti & 1 & Medicago truncatula & France (Var) & 22 \\
\hline A 27 & Genomic species 2 & 2 & Medicago truncatula & France (Aude) & 22 \\
\hline A 34 & Genomic species 2 & 2 & Medicago truncatula & France (Aude) & 22 \\
\hline A $321^{\mathrm{T}}$ & Genomic species 2 & 2 & Medicago truncatula & France (Aude) & 22 \\
\hline V 113 & Genomic species 2 & 2 & Medicago truncatula & France (Var) & 22 \\
\hline V 22 & Genomic species 2 & 2 & Medicago truncatula & France (Var) & 22 \\
\hline V 25 & Genomic species 2 & 2 & Medicago truncatula & France (Var) & 22 \\
\hline V 214 & Genomic species 2 & 2 & Medicago truncatula & France (Var) & 22 \\
\hline \multicolumn{6}{|l|}{ Reference strains } \\
\hline M3 & Genomic species 2 & 2 & Medicago orbicularis & Syria & 7 \\
\hline M104 & Genomic species 2 & 2 & Medicago truncatula & Syria & 7 \\
\hline RCR 2011 (= SU $47=$ NZP4009 = LMG 6130) & S. meliloti & 1 & Medicago sativa & Australia & 5,18 \\
\hline USDA $205^{\mathrm{T}}$ & S. fredii & $\mathrm{ND}^{b}$ & Glycine max & $\begin{array}{l}\text { People's Republic } \\
\text { of China }\end{array}$ & 5,18 \\
\hline
\end{tabular}

${ }^{a}$ PCR-RFLP groups 1 and 2 and the genomic species have been described previously (22).

${ }^{b} \mathrm{ND}$, not determined.

nodulate Medicago species should be placed into at least two species.

In this study, nine strains which were obtained from annual Medicago species (including two strains from Eardly et al. [7]) and were genomically distinct from $S$. meliloti were compared with reference strains of $S$. meliloti and the closely related species $S$. fredii.

Consistent with the recommendations for Rhizobiaceae taxonomy (12), we used cultural characteristics (from auxanographic and biochemical tests), genomic characteristics (16S rRNA sequence data), and symbiotic characteristics to establish the taxonomic status of the organisms studied.

\section{MATERIALS AND METHODS}

Bacterial strains. The 15 Sinorhizobium strains which we studied are listed in Table 1. Eleven strains, which were identified as either $S$. meliloti or genomic species 2 strains, were isolated from two $M$. truncatula $\mathbf{L}$. ecotypes which are found at two sites in southern France, named Aude and Var and identified as A and $\mathrm{V}$, respectively. Two strains isolated from $M$. truncatula and Medicago orbicularis in Syria were also included; these strains are representatives of division B as defined by isoenzyme characteristics (7). S. fredii USDA 205 is the type strain of the type species of the genus Sinorhizobium (5). In phenotypic tests, we used strain RCR 2011 as the reference strain for $S$. meliloti $(5,18)$. This strain, which was included in division A of Eardly et al. (7), is closely related to $S$. meliloti ATCC $9930^{\mathrm{T}}(\mathrm{T}=$ type strain) and is currently used as a reference strain for $S$. meliloti (5).

All strains were maintained on yeast extract-mannitol (YEM) medium (27). Unless otherwise stated, cultures were incubated at $28^{\circ} \mathrm{C}$

DNA extraction. Bacterial DNA was extracted from $150-\mathrm{ml}$ stationary-phase TY broth cultures as described by Brenner et al. (1). TY medium contained (per liter of distilled water) $10 \mathrm{~g}$ of Bacto Tryptone (Difco) and $6 \mathrm{~g}$ of yeast extract (Difco), as well as $6 \mathrm{mM} \mathrm{CaCl} 2 \cdot 2 \mathrm{H}_{2} \mathrm{O}$.

16S rRNA gene sequencing. The $16 \mathrm{~S}$ rRNA gene of strain $\mathrm{A} 321^{\mathrm{T}}$ was amplified by PCR by using the procedure of Mullis and Faloona (20). The following two prokaryote-specific primers were used: FGPS6-255 (5'-TGGAAAGCTTG ATCCTGGCT-3') and FGPS1509'-153 (5'-AAGGAGGGGATCCAGCCGCA $-3^{\prime}$ ) (the underlined sequences are HindIII and Bam HI restriction sites, respectively). The amplified fragments were purified with a Geneclean kit (Bio 101, La Jolla, Calif.) according to the manufacturer's instructions. The PCR fragments were cleaved with endonucleases HindIII and BamHI and ligated into the Bluescript $\mathrm{SK}^{-}$vector (Stratagene, La Jolla, Calif.) digested by the same enzymes. Plasmid purification from host strain $\mathrm{DH} 5 \alpha \mathrm{F}^{\prime}$ was performed with QIAGEN midi-prep columns (Diagen, Düsseldorf, Germany). Five clones were pooled for the sequencing reaction in order to obscure possible errors due to the Taq polymerase.

Sequencing was performed by using the dideoxy chain termination method of Sanger et al. (24). A 77 sequencing kit (Pharmacia LKB, Uppsala, Sweden) was used.

DNA sequence analysis. 16S rRNA sequences were aligned by using the
Clustal multiple-alignment program (13). Sites involving gaps were excluded from all analyses. Evolutionary distances corrected for multiple substitutions were computed by using Kimura's two-parameter model (17). A phylogenetic tree was inferred by using the neighbor-joining (NJ) method (23). The NJ method is considered one of the most efficient methods for recovering phylogenetic trees (23). The 16S rRNA sequences of the following organisms belonging to the Rhizobiaceae and related bacteria were used for comparison (GenBank accession numbers are in parentheses): Rhizobium ciceri UPM-Ca $7^{\mathrm{T}}$ (UO7934), Rhizobium galegae LMG $6214^{\mathrm{T}}$ (X67226), Rhizobium huakuii IAM 14158 ${ }^{\mathrm{T}}$ (D12797), Rhizobium leguminosarum A LMG 9518 (X67233), Rhizobium loti A LMG 6125 $5^{\mathrm{T}}$ (X67229), Rhizobium loti B LMG 4284 (X67230), Rhizobium mediterraneum UPM-Ca36 ${ }^{\mathrm{T}}$ (L38825), Rhizobium tropici (IFO15247) (D11344), Rhizobium tropici IIB LMG 9517 (X67234), Rhizobium ORS 1001-Cluster U (X68389), Rhizobium sp. strain LMG 9509 (X67232), S. meliloti LMG 6133 ${ }^{\mathrm{T}}$ (=

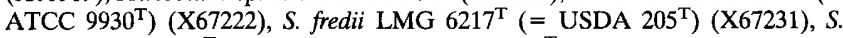
teranga ORS $1009^{\mathrm{T}}$ (X68387), S. saheli ORS $609^{\mathrm{T}}$ (X68391), Bradyrhizobium japonicum NZP 5549 ${ }^{\mathrm{T}}$ (X66024), Azorhizobium caulinodans LMG 6465 (X67221), Agrobacterium rhizogenes LMG $150^{\mathrm{T}}$ (X67224), Agrobacterium nubi ATCC $13335^{\mathrm{T}}$ (D14503 and D01259), Agrobacterium tumefaciens LMG $198^{\mathrm{T}}$ (X67223), Agrobacterium vitis LMG 257 (D14502 and D1258), Brucella abortus (X13695), Mycoplana dimorpha NCIB $9439^{\mathrm{T}}$ (D12786), Ochrobactrum anthropi CIP $14970^{\mathrm{T}}$ (D12794), Phyllobacterium myrsinacearum NCIB 12127 (D12789), and Rochalimaea vinsonii (M73230).

Phenotypic tests (i) Growth characteristics. In order to determine the capacity of the organisms to grow at different $\mathrm{pH}$ values and temperatures and their tolerance to sodium chloride, starter cultures were grown at $28^{\circ} \mathrm{C}$ to the log phase $\left(10^{9}\right.$ bacteria per $\left.\mathrm{ml}\right)$ in YEM broth, and 5-ml portions of YEM broth were inoculated in triplicate with $50-\mu \mathrm{l}$ portions of the starter cultures. The presence or absence of growth was scored in inoculated tubes after 3 days. The $\mathrm{pH}$ tolerance of strains was determined by using YEM broth preparations in which the $\mathrm{pH}$ values were adjusted to $4.0,5.0,6.0,9.0$, and 10 ( $\pm 0.1 \mathrm{pH}$ unit) by adding $\mathrm{HCl}$ or $\mathrm{NaOH}$. Growth was also examined at 37 and $42^{\circ} \mathrm{C}$. Sodium chloride tolerance was determined by using YEM broth preparations in which the concentrations of $\mathrm{NaCl}$ were 2 and $3 \%$ (wt/vol). Control cultures were grown under standard conditions in YEM medium $\left(0.1 \%\right.$ [wt/vol] $\left.\mathrm{NaCl}, \mathrm{pH} 7,28^{\circ} \mathrm{C}\right)$.

(ii) Antibiotic susceptibility. Triplicate antibiotic resistance tests were performed by measuring the diameters of inhibition zones on YEM agar plates containing the following antibiotic discs: polymyxin $(300 \mathrm{mg})$, streptomycin $(10$ $\mathrm{mg}$ ), tetracycline $(30 \mathrm{mg})$, neomycin $(30 \mathrm{mg})$, chloramphenicol $(30 \mathrm{mg})$, nalidixic acid $(30 \mathrm{mg})$, vancomycin $(30 \mathrm{mg})$, and penicillin $\mathrm{G}(6 \mathrm{mg})$ (SANOFI Diagnostic Pasteur, Marnes-la-Coquette, France). The susceptibilities of the strains were deduced from the antibiograms (SANOFI Diagnostic Pasteur) on the basis of the diameters of the inhibition zones.

(iii) Biochemical and auxanographic tests. A total of 49 carbohydrates were used as sole carbon sources in API $50 \mathrm{CH}$ microtube system rapid procedures (BioMérieux, La Balme Les Grottes, France). The preparations were inoculated as recommended by the manufacturer, and the test strips were incubated at $28^{\circ} \mathrm{C}$. Results were scored every day for 5 days.

(iv) Data analysis. The genetic distance between each possible pair of isolates tested for auxanographic and biochemical characteristics was estimated by comparing the phenotypic variables, using the Jaccard similarity coefficient (26). In this procedure the sum of effective matches is computed and divided by the total 
S. teranga
S. saheli
S. fredii
S. meliloti
CC 169
A 321

S. teranga

S.saheli

S. fredii

S. meliloti

CC 169

A 321

S. teranga

S. saheli

$S$. fredii

s. meliloti

CC 169

A 321

\section{S. teranga}

S. saheli

S. fredii

S. meliloti

CC 169

A 321

S. teranga
S. saheli
S. fredii
S. meliloti
CC 169
A 321

A 321

S. teranga

S. saheli

S. fredii

S. meliloti

A 321

\section{S. teranga}

S. saheli

$S$. Eredii

S. meliloti

A 321

S. teranga

$S$. saheli

S. Eredii

S. meliloti

A 321

S. teranga

$S$. saheli

$S$. Fredii

S. meliloti

A 321

S. teranga

S. saheli

S. Eredii

S. meliloti

A 321

S. teranga

S. saheli

S. fredii

S. meliloti

A 321

S. teranga

S. saheli

S. fredii

S. meliloti

A 321

1

11

21

31

41

51

110

- - - - - - - - -

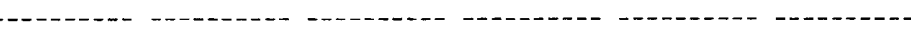

AACGAACGCT GGCGGCAGGC TTAACACATG CAAGTCGAGC GCCCCGCAAG GgGAGCGGCA

-

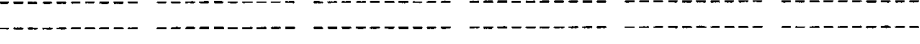

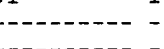

111

- - - - - - - - - - - - - - - - - - - - - - - GACGGGTGAG TAACGCGTGG GAATCTACCC TTTTCTACGG AATAACGCAG GGAAACTTGT

$\begin{array}{llllll}121 & 131 & 141 & 151 & 161 & 171\end{array}$

GCTAATACCG TATAAGCCCT TCGgGgGAAA GATTTATCGG GAAAGgATGA GCCCGCGTTG

$\begin{array}{llllll}181 & 191 & 201 & 211 & 221 & 231\end{array}$ 200- - - -

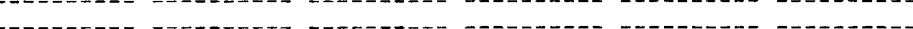
GATTAGCTAG TTGGTGGGGT AAAGGCCTAC CAAGGCGACG ATCCATAGCT GGTCTGAGAG
241
251
261
271
281
291

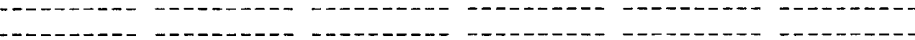

GATGATCAGC CACATTGGGA CTGAGACACG GCCCAAACTC CTÁGGGGGG CAGCAGTGGG

$\begin{array}{llllll}301 & 311 & 321 & 331 & 341 & 351\end{array}$

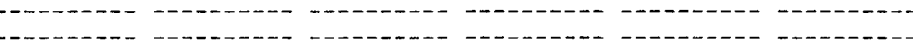
-..-.GAATATTGGA CAATGGGCGC AAGCCTGATC CAGCCATGCC GCGTGAGTGA TGAAGGCCCT
361
371
381
391
401
411 AGGGTTGTAA AGCTCTTTCA CCGGTGAAGA TAATGACGGT AACCGGAGAA GAAGCCCCGG 431 441 451 461 471 CTAACTTCGT GCCAGCAGCC GCGGTAATAC GAAGGGGGCT AGCGTTGTTC GGAATTACTG $\begin{array}{llllll}481 & 491 & 501 & 511 & 521 & 531 \\ - & -1 & - & -1\end{array}$ $\begin{array}{llll}- & \end{array}$ -

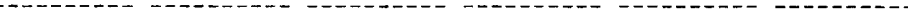
GGCGTAAAGC GCACGTAGGC GGATTGTTAA GTGAGGGGTG AAATCCCAGG GCTCAACCCT

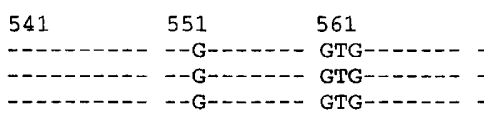

$571 \quad 581$

591 GGAACTGCCT TTCATACTGG CAATCTAGAG TCCAGAAGAG GTGAGTGGAA TTCCGAGTGT
601
611
621
631
641
651 AGAGGTGAAA TTCGTAGATA TTCGGAGGAA CACCAGTGGC GAAGGCGGCT CACTGGTCTG

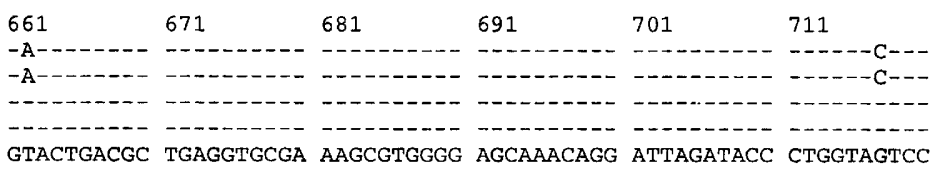




\begin{tabular}{|c|c|c|c|c|c|c|}
\hline & 721 & 731 & 741 & 751 & 761 & 771 \\
\hline S. teranga & ---------- & $-----1---$ & --------- & $----C---$ & $------\infty$ & - - - - \\
\hline S. sahe & - & ---------- & $-\cdots------$ & $----1-\infty$ & -------- & - \\
\hline S. fred & - & - & -------- & $---n-1---$ & $---\cdots---\infty$ & 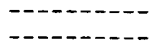 \\
\hline $\begin{array}{l}\text { S. mel } \\
\text { A } 321\end{array}$ & ACGCCGTAAA & CGATGAATGT & TAGCCGTCGG & GCAGTTTACT & GTTCGGTGGC & GCAGCTAACG \\
\hline & 781 & 791 & 801 & 811 & 821 & 831 \\
\hline S. teranga & 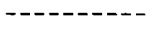 & --------- & --------- & ---- & --- & ------- \\
\hline S. sah & $------\cdots$ & -------- & $------\cdots$ & -------- & $-\cdots-\infty-\infty$ & $---1---1$ \\
\hline s. fred & ------- & -------- & -------- & --------- & $-\cdots-$ & ---------- \\
\hline S. meliloti & 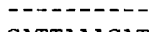 & $---\infty-----$ & $-------0-$ & $---1-0---1$ & 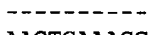 & - - - \\
\hline A 321 & CATTAAACAT & TCCGCCTGGG & GAGTACGGTC & GCAAGATTAA & AACTCAAAGG & AATTGACGGG \\
\hline & $841 \star$ & 851 & 861 & 871 & 881 & 891 \\
\hline S. ter & ---- & 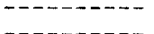 & $\cdots$ & $--\infty-$ & -- & -- \\
\hline $\begin{array}{l}\text { s. sa } \\
\text { s. fr }\end{array}$ & -- & - & -- & - & & \\
\hline S. meli & $---\quad-----$ & -------- & ---------- & --- & $----1-$. & $\cdots----$ \\
\hline A 321 & GGCCCGCACA & AGCGGTGGAG & CATGTGGTTT & AATTCGAAGC & AACGCGCAGA & ACCTTACCAG \\
\hline
\end{tabular}

\section{S. teranga \\ S. saheli \\ S. meliloti \\ A 321}

\begin{tabular}{|c|c|c|c|c|c|}
\hline & 911 & & 1 & 941 & \\
\hline & -- & -12 & GT & $----m$ & \\
\hline & -1 & --- & --- & -- & \\
\hline & $-\infty$ & --- & $---G$ & -- & -7 \\
\hline & - & $-\mathrm{C}-----$ & - & -- & -1 \\
\hline & CGATCG & TAGGAGAG & ТССТАТ & PTCGGC & GAG \\
\hline
\end{tabular}

S. teranga
S. saheli
S. fredii
S. meliloti
A 321

\begin{tabular}{|c|c|c|c|c|c|}
\hline 961 & 971 & 981 & 991 & 1001 & 1011 \\
\hline ---- - - - - & $--\cdots----$ & $\rightarrow--\cdots+-\cdots$ & --+----- & -------- & $--\cdots-----$ \\
\hline 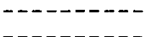 & 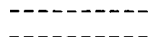 & $\cdots-\cdots-1$ & $----\cdots--n-1$ & --------- & $---1-----$ \\
\hline 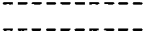 & 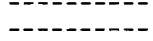 & 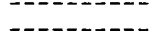 & 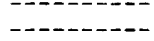 & m-n & 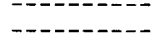 \\
\hline
\end{tabular}

S. teranga
S. saheli
S. fredii
S. meliloti
A 321

\begin{tabular}{|c|c|c|c|c|c|}
\hline & * & 1041 & 51 & 1061 & 1071 \\
\hline & & ------- & G- - - & - & \\
\hline & - & -- & $-\rightarrow$ TG-- --- & ---- & -- \\
\hline & -- & --- & $-\mathrm{T}--$ & - & -1 \\
\hline & TCG & 8 & $\overline{G G G}$ & $\triangle A G G$ & SACTGCC \\
\hline
\end{tabular}

S. teranga
S. saheli
S. fredii
S. meliloti
A 321

\begin{tabular}{llllll}
1081 & 1091 & 1101 & 1111 & 1121 & 1131 \\
\hline & & 11 & & \\
\hline & & &
\end{tabular}

\begin{tabular}{|c|c|c|c|c|c|c|}
\hline & 1141 & 1151 & 1161 & 1171 & 1181 & 1191 \\
\hline s. teranga & $-----1---$ & $----1--1$ & $----1--1--$ & --------- & 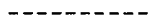 & ----ー---- \\
\hline S. saheli & $----\cdots--$ & - - - - - & 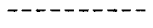 & 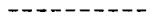 & $--\cdots-\cdots--$ & $\ldots-\ldots-\cdots$ \\
\hline S. fredii & -----n- & $-\cdots-\cdots---$ & $-----\cdots--$ & $-\cdots----\cdots$ & $\cdots \cdots-\cdots$ & ---------- \\
\hline s. meliloti & $--\cdots----$ & --------- & --------- & 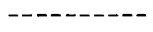 & $--\infty---\cdots$ & $-----\cdots--$ \\
\hline A 321 & TACACACGTG & CTACAATGGT & GGTGACAGTG & GGCAGCGAGA & CCGCGAGGTC & GAGCTAATCT \\
\hline
\end{tabular}

\begin{tabular}{|c|c|c|c|c|c|c|}
\hline & 1201 & 1211 & 1221 & 1231 & 1241 & 1251 \\
\hline s. teranga & --------1 & ---------- & ----n---- & ---------- & --------- & --- \\
\hline S. saheli & $--\cdots-\cdots$ & $----\cdots---$ & $-\cdots--\cdots$ & $-\cdots-\cdots-\cdots$ & ---- & --- \\
\hline s. fredii & -------- & ---------- & - - - - - & 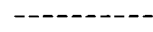 & $---\infty$ & -- \\
\hline s. meliloti & ---------- & 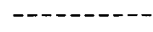 & --------- & $-\cdots----n$ & $-\cdots-\cdots--$ & -------- \\
\hline A 321 & CCAAAAGCCA & TCTCAGTTCG & GATTGCACTC & TGCAACTCGA & GTGCATGAAG & TTGGAATCGC \\
\hline
\end{tabular}

\begin{tabular}{|c|c|c|c|c|c|c|}
\hline & 1261 & 1271 & 1281 & 1291 & 1301 & 1311 \\
\hline S. ter & $-\cdots-----$ & $-\cdots--\cdots---$ & $--\cdots-\cdots$ & ------ & $\ldots$ & ---- \\
\hline S. sah & $---\cdots$ & -- & ---------- & -- & & 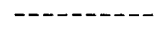 \\
\hline fred & -------- & --------- & --- & - & & -- \\
\hline 5. meli & - & 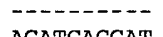 & 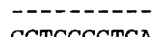 & 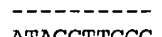 & - & 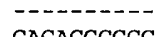 \\
\hline 321 & IAGTAATCGC & AGATCAGCAT & rGCGGTGA & GT' & GCCT & $\mathrm{ACACCG}$ \\
\hline
\end{tabular}

\begin{tabular}{|c|c|c|c|c|c|}
\hline \multirow[t]{2}{*}{321} & 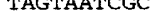 & $20+2 x+20$ & (2) & $\cdots$ & \\
\hline & 1321 & 1331 & 1341 & 1351 & 1361 \\
\hline S. teranga & --------- & $\ldots+\cdots-\infty$ & 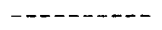 & $-m---m$ & -- \\
\hline S. sahe & -------- & --n----- & --------- & --------- & \\
\hline S. fredii & $\ldots$ & -------- & $-\cdots-----$ & $----\cdots---$ & \\
\hline S. meli & $------n$ & $-----\cdots--$ & -------- & $-\cdots---\cdots$ & --1 \\
\hline \multirow[t]{2}{*}{ A 321} & GTCACACCAT & GGGAGTTGGT & TCTACCCGAA & GGTAGTGCGC & TAI \\
\hline & 1381 & 1391 & 1401 & & 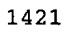 \\
\hline S. $t$ & --------- & $-----\cdots-$ & $-\cdots+--$ & $-+--n---$ & --- \\
\hline S. sah & ------- & $-\cdots-\cdots-\cdots$ & --------- & ---------- & --- \\
\hline S. fredii & $--\cdots-----$ & -------- & ------- & -------- & --- \\
\hline S. meliloti & $-0-1-1$ & $-\ldots--\infty$ & $--1,--$ & $----\cdots$ & $\cdots$ \\
\hline A 321 & ACCACGGTAG & GGTCAGCGAC & TGGGGTGAAG & TCGTAACAAG & GTA \\
\hline
\end{tabular}

FIG. 1. Alignment of the total 16S rRNA gene sequence of strain A $321^{\mathrm{T}}$ (genomic species 2) with sequences of $S$. fredii USDA $205^{\mathrm{T}}$, $S$. meliloti ATCC 9930 ${ }^{\mathrm{T}}$, $S$. saheli ORS $609^{\mathrm{T}}$, and $S$. teranga ORS $1009^{\mathrm{T}}$. The partial sequence of isolate CC169 (8) extends from position 17 to position 276 . Gaps are indicated by asterisks. 
TABLE 2. Homology matrix for complete 16S rRNA sequences

\begin{tabular}{lccccc}
\hline \multirow{2}{*}{ Organism } & \multicolumn{5}{c}{ No. of differences or \% homology } \\
\cline { 2 - 6 } & S. saheli & S. teranga & S. fredii & S. meliloti & Strain A 321 \\
\hline S. saheli & & 15 & 8 & 20 & 24 \\
S. teranga & 98.9 & & 19 & 31 & 31 \\
S. fredii & 99.4 & 98.6 & & 14 & 16 \\
S. meliloti & 98.5 & 97.7 & 99.0 & & 4 \\
Strain A 321 & 98.2 & 97.7 & 98.8 & 99.7 & \\
\hline
\end{tabular}

a The values on the upper right are the numbers of observed differences (nucleotides plus gaps), and the values on the lower left are the percentages of similarity corrected for multiple base changes by the method of Kimura (17) (gaps were excluded from the analysis).

possible number of matches for each pairwise calculation. Clustering from a matrix of pairwise genetic distances was performed by the unweighted pair group method with arithmetic averages (26).

(v) Symbiotic properties. Strains obtained from $M$. truncatula, strain RCR 2011 obtained from $M$. sativa, and strain M3 obtained from $M$. orbicularis were tested for the ability to nodulate and fix nitrogen on $M$. truncatula (ecotype Aude) and $M$. polymorpha (ecotype Combaillaux). Seeds were surface sterilized in $1 \%$ (wt/vol) calcium hypochlorite for $2 \mathrm{~min}$, rinsed with sterile water, and then scarified. These seeds were germinated for $72 \mathrm{~h}$ on $0.7 \%$ (wt/vol) agar medium in a growth chamber at $28^{\circ} \mathrm{C}$, and germinated seeds were placed aseptically in Gibson tubes (11) supplemented with a nitrogen-free plant nutrient solution (3) Each tube was inoculated with a rhizobial suspension from an early-stationaryphase culture. Uninoculated plants and plants to which nitrogen $[10 \mathrm{mM}$ $\mathrm{Ca}\left(\mathrm{NO}_{3}\right)_{2}$ ] was added were used as controls. Fifteen replicates were prepared for each treatment. After 50 days, the plants were harvested, the number of nodules was counted, and the nodule dry weight was determined after the nodules were dried for $48 \mathrm{~h}$ at $70^{\circ} \mathrm{C}$.

Nucleotide sequence accession number. The $16 \mathrm{~S}$ rRNA sequence of strain A $321^{\mathrm{T}}$ which we determined has been deposited in the GenBank data library under accession number L39882.

\section{RESULTS}

DNA analysis. The total 16S rRNA sequence of genomic species 2 isolate A $321^{\mathrm{T}}$ was determined. This sequence was aligned and compared with the $16 \mathrm{~S}$ rRNA sequences of other members of the alpha 2 subclass of the Proteobacteria. From the results of this comparison of aligned sequences we deduced that on the basis of its 16 S ribosomal DNA (rDNA) sequence strain A $321^{\mathrm{T}}$ clusters with the Sinorhizobium lineage (data not shown). Figure 1 shows the $16 \mathrm{~S}$ rDNA sequence of isolate $\mathrm{A}$ $321^{\mathrm{T}}$ aligned with the $16 \mathrm{~S}$ rDNA sequences of $S$. meliloti ATCC $9930^{\mathrm{T}}, S$. fredii USDA $205^{\mathrm{T}}$, S. teranga ORS $1009^{\mathrm{T}}$, and S. saheli ORS $609^{\mathrm{T}}$. Table 2 shows similarity values and observed numbers of nucleotide differences for the sequences of Sinorhizobium species. The $16 \mathrm{~S}$ rDNA of A $321^{\mathrm{T}}$ was most similar to the $16 \mathrm{~S}$ rDNA of $S$. meliloti (level of similarity, $99.7 \%$, corresponding to four nucleotide substitutions and one deletion). The four nucleotide substitutions occurred in two variable regions of the gene (Fig. 1), at position 133 and from position 923 to position 933; the deletion was located at position 845.

Evolutionary distances between members of the Rhizobiaceae and some related genera were computed, and a phylogenetic tree was constructed by using the NJ algorithm and the pairwise evolutionary distances (Fig. 2). Bootstrap confidence intervals of the various clusters on the $\mathrm{NJ}$ tree were estimated from 1,000 replications (9). Bootstrap values greater than $95 \%$ are shown in Fig. 2. The results of this analysis clearly placed the Sinorhizobium species in a monophyletic cluster for $99 \%$ of the bootstrap replicates. Isolate A $321^{\mathrm{T}}$ and $S$. meliloti were clustered on a monophyletic lineage within the genus Sinorhizobium in $100 \%$ of the bootstrap replicates.

Phenotypic tests. All of the isolates studied were gram-negative, motile, non-spore-forming, rod-shaped bacteria. On
YEM medium, they were mucous, and they acidified the medium, changing the $\mathrm{pH}$ from 7 to 5 . The generations time were between 3 and $5 \mathrm{~h}$. All of the isolates grew at $28^{\circ} \mathrm{C}$ at pH 5 to 10 and at $37^{\circ} \mathrm{C}$ but not at $42^{\circ} \mathrm{C}$. Strain RCR 2011 and the $S$. meliloti isolates grew at $\mathrm{pH} \mathrm{4,} \mathrm{whereas} \mathrm{all} \mathrm{of} \mathrm{the} \mathrm{genomic}$ species 2 isolates except M104 and $S$. fredii did not grow at this $\mathrm{pH}$. All of the isolates tolerated $2 \%$ (wt/vol) NaCl. S. meliloti isolates grew in the presence of $3 \%$ (wt/vol) $\mathrm{NaCl}$, while the growth of genomic species 2 isolates and $S$. fredii was variable under these conditions.

The results of tests to determine resistance to eight antibiotics showed that all of the isolates were resistant to nalidixic acid and penicillin $\mathrm{G}$ and susceptible to polymyxin. Strain RCR 2011 (S. meliloti) and strain USDA $205^{\mathrm{T}}$ ( $S$. fredii) were susceptible to chloramphenicol. Strain USDA $205^{\mathrm{T}}$ was the only strain that was susceptible to streptomycin. Genomic species 2 strains could be distinguished by their susceptibility to neomycin. In contrast, chloramphenicol susceptibility, tetracycline susceptibility, and vancomycin susceptibility were variable depending on the isolate and could not be used to separate group 1 and 2 rhizobia.

A total of 45 carbon sources were tested, and the following

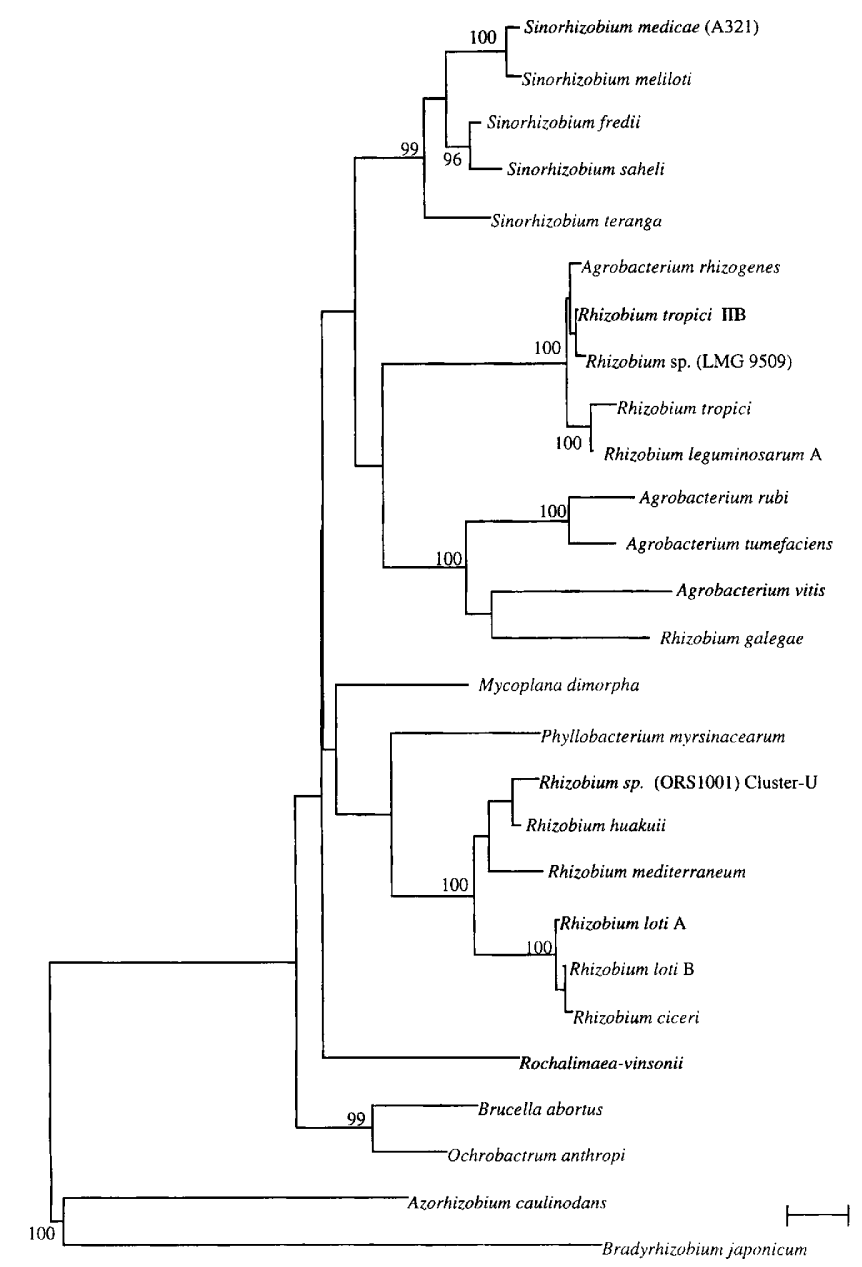

FIG. 2. Phylogenetic relatedness of species belonging to the alpha 2 subclass of the Proteobacteria as determined with the NJ method and nucleic acid pairwise distances. Horizontal distances are proportional to levels of evolutionary divergence expressed as numbers of substitutions per site; vertical separations are for clarity only. Bootstrap probability values greater than $95 \%$ are indicated at the branch points. Bar $=0.0071$ substitution per site 
TABLE 3. Carbon sources that can be used to distinguish taxa

\begin{tabular}{|c|c|c|c|c|c|c|c|c|c|c|c|}
\hline \multirow[b]{2}{*}{ Taxon } & \multicolumn{11}{|c|}{ Utilization of: } \\
\hline & Glycerol & Melibiose & Lyxose & Xylitol & Tagatose & $\begin{array}{l}\text { 2-Keto- } \\
\text { gluconate }\end{array}$ & Dulcitol & $\begin{array}{c}\text { Melezi- } \\
\text { tose }\end{array}$ & $\begin{array}{l}\text { Sorbose and } \\
\text { D-fucose }\end{array}$ & D-Arabinose & $\begin{array}{l}\text { D-Xylose, } \\
\text { salicin, } \\
\text { and ribose }\end{array}$ \\
\hline \multicolumn{12}{|l|}{ Reference strains } \\
\hline S. fredii USDA $205^{\mathrm{T}}$ & $+^{a}$ & + & - & - & - & - & - & - & - & + & + \\
\hline S. meliloti RCR 2011 & + & + & - & + & + & + & + & - & + & - & + \\
\hline \multicolumn{12}{|c|}{$\begin{array}{l}\text { Strains from annual Medicago } \\
\text { spp. (genomic species } 2)^{b}\end{array}$} \\
\hline PCR-RFLP group $1^{c}$ & + & + & $\mathrm{v}$ & - & + & + & $\mathrm{v}$ & $\mathrm{v}$ & + & - & + \\
\hline PCR-RFLP group $2^{c}$ & $\mathrm{v}$ & $\mathrm{v}$ & $\mathrm{v}$ & + & + & + & $\mathrm{v}$ & $\mathrm{v}$ & - & - & - \\
\hline
\end{tabular}

${ }^{a}+$, all strains are positive; - , all strains are negative; $\mathrm{v}$, variable.

${ }^{b}$ A total of 13 isolates obtained from $M$. truncatula and $M$. orbicularis (Table 1 ).

${ }^{c}$ See Table 1 .

10 were not assimilated by any isolate: $L$-arabinose, amygdalin, inulin, gluconate, 5-keto-gluconate, $\alpha$-methyl-D-glucoside, glycogen, $\alpha$-methyl-D-mannoside, starch, and L-xylose. The following 25 compounds were used as sole carbon sources by all of the isolates tested: adonitol, D-arabitol, L-arabitol, arbutin, D-cellobiose, erythriol, esculin, fructose, L-fucose, galactose, $\beta$-gentiobiose, $N$-acetylglucosamine, glucose, inositol, lactose, maltose, mannitol, mannose, D-raffinose, rhamnose, sorbitol, sucrose, trehalose, D-turanose, and $\beta$-methyl-D-xyloside. The results of distinctive auxanographic tests are shown in Table 3.

Numerical analysis of phenotypic data. The numerical analysis of phenotypic data included data from 49 auxanographic tests, as well as data for tolerance to $\mathrm{NaCl}, \mathrm{pH}$, and antibiotics; a total of 63 characteristics were used in this analysis. The resulting dendrogram is presented in Fig. 3, and this dendrogram shows that the Medicago isolates were separated into two major groups. The first group contained S. meliloti RCR 2011 and four isolates from $M$. truncatula received as $S$. meliloti. The second group contained eight isolates from $M$. truncatula and the isolate from $M$. orbicularis (isolate M3), all of which were previously identified as members of genomic group 2 . The two groups diverged at a genetic distance of approximately 0.13 . The $S$. fredii strain branched far from all of the Medicago isolates.

Symbiotic properties on $M$. polymorpha and $M$. truncatula. Isolates obtained from $M$. truncatula and reference isolates RCR 2011 and M3 were tested for the ability to form nodules

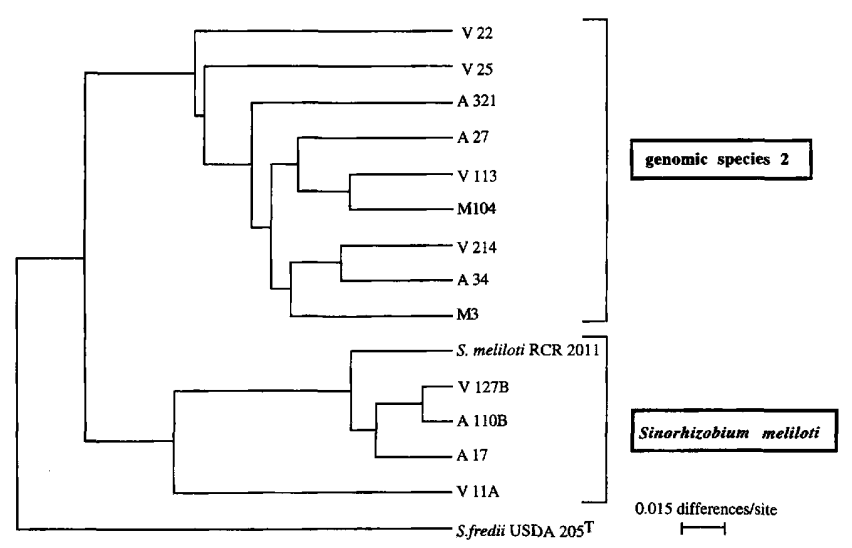

FIG. 3. Dendrogram showing the genetic distances between isolates obtained from annual Medicago species and two reference strains, $S$. meliloti RCR 2011 and $S$. fredii USDA $205^{\mathrm{T}}$, based on a numerical unweighted pair group with arithmetic average analysis of the results of 63 phenotypic tests. on $M$. polymorpha and $M$. truncatula. Plant growth (shoot dry weight) on mineral medium without combined nitrogen was used to estimate nitrogen fixation efficiency (Table 4).

On M. truncatula, all of the bacterial isolates tested induced pink well-developed nodules, and the shoot dry weights of inoculated plants were significantly greater than the shoot dry weights of uninoculated controls, except for plants inoculated with isolate $\mathrm{V} 11 \mathrm{~A}$. There was no significant difference between plants inoculated with $S$. meliloti and plants inoculated with genomic species 2 . On $M$. polymorpha, all of the isolates tested formed nodules. However, the genomic species 2 isolates formed pink, efficient nodules, and all of the $S$. meliloti isolates, including RCR 2011, formed rudimentary, inefficient, white nodules. The shoot dry weights for the $M$. polymorpha-S. meliloti associations were not significantly different from the shoot dry weights of uninoculated controls.

\section{DISCUSSION}

The genus Medicago comprises more than 60 different species, including annuals and perennials. The primary center of diversity of the genus is in the Mediterranean basin (19). The biodiversity of sinorhizobia which naturally form symbiotic associations with annual Medicago species was investigated previously by workers who used phenotypic and genomic approaches $(3,7,22)$. These studies revealed that there are two groups of Medicago-infective Sinorhizobium isolates. The first group (group A of Eardly et al. [7], group I of Brunel et al. [3], and group 1 of Rome et al. [22]) corresponds to $S$. meliloti. The second group (group B of Eardly et al. [7], group II of Brunel et al. [3], and group 2 of Rome et al. [22]) represents a separate genomic species. The purpose of this study was to establish the taxonomic position of this genomic species by using phenotypic tests and 16S rRNA sequencing.

16S rRNA sequence analysis data are currently used to measure phylogenetic relationships. Relatively well-conserved regions of the 16S rRNA sequence can be used to infer natural relationships between distantly related species, whereas variable regions can be used to analyze closely related species (14). Comparisons of the $16 \mathrm{~S}$ rRNA sequences of species belonging to the Rhizobiaceae have demonstrated that this approach can be used to classify isolates at the species and higher levels (18, 28-30). In the present study, the total 16S rRNA sequence of a genomic species 2 isolate was determined to estimate the relationship between this genomic species and the other members of the genus Sinorhizobium. After alignment and comparison of sequences we found that genomic species 2 strain A $321^{\mathrm{T}}$ and the type strain of $S$. meliloti had distinct sequences 
TABLE 4. Symbiotic properties of isolates on $M$. truncatula and M. polymorpha

\begin{tabular}{|c|c|c|c|c|}
\hline \multirow[b]{2}{*}{ Strain or prepn } & \multicolumn{2}{|c|}{ M. polymorpha } & \multicolumn{2}{|c|}{ M. truncatula } \\
\hline & $\begin{array}{l}\text { Plant dry wt } \\
\left(10^{-3}, \mathrm{~g}\right)\end{array}$ & No. of nodules & $\begin{array}{c}\text { Plant dry wt } \\
\left(10^{-3}, \mathrm{~g}\right)\end{array}$ & No. of nodules \\
\hline Control with $\mathrm{N}(10 \mathrm{mM})$ & $34 \pm 11.3^{a}$ & 0 & $146 \pm 47.6$ & 0 \\
\hline Uninoculated control & $1.4 \pm 0.64$ & 0 & $9 \pm 8.8$ & 0 \\
\hline \multicolumn{5}{|c|}{$S$. meliloti isolates (PCR-RFLP group 1) } \\
\hline RCR 2011 & $2.3 \pm 0.94$ & $4.5 \pm 2.5^{a}$ & $38 \pm 17.5$ & $3 \pm 1.3$ \\
\hline A 13 & $3.0 \pm 1.0$ & $11 \pm 5.87$ & $18 \pm 17.4$ & $3 \pm 1.5$ \\
\hline A 17 & $2.3 \pm 0.86$ & $6.2 \pm 3.46$ & $53 \pm 24.5$ & $3 \pm 1.45$ \\
\hline A $110 \mathrm{~B}$ & $1.4 \pm 0.92$ & $7.3 \pm 4.8$ & $58 \pm 27.5$ & $3 \pm 1$ \\
\hline V $11 \mathrm{~A}$ & $2.7 \pm 0.94$ & $7.7 \pm 4.4$ & $5 \pm 2.25$ & $3 \pm 1.2$ \\
\hline V $127 \mathrm{~B}$ & $2.2 \pm 0.72$ & $4.6 \pm 4.7$ & $69 \pm 17.6$ & $4 \pm 1.5$ \\
\hline \multicolumn{5}{|c|}{ Genomic species 2 isolates (PCR-RFLP group 2) } \\
\hline A 27 & $27.75 \pm 4.6$ & $5.6 \pm 3.6$ & $70 \pm 23.8$ & $4 \pm 1.7$ \\
\hline A $321^{\mathrm{T}}$ & $26 \pm 3.5$ & $7.9 \pm 3.8$ & $74 \pm 24.5$ & $4 \pm 1.7$ \\
\hline V 22 & $27 \pm 2.1$ & $8.4 \pm 1.55$ & $49 \pm 22.5$ & $3 \pm 1.4$ \\
\hline $\mathrm{V} 25$ & $25 \pm 5.2$ & $6 \pm 1.6$ & $67 \pm 23.9$ & $3 \pm 1.6$ \\
\hline V 214 & $15.1 \pm 6.2$ & $9.54 \pm 3.4$ & $53 \pm 17.5$ & $4 \pm 2$ \\
\hline V 113 & $26.2 \pm 4.5$ & $6.5 \pm 2.7$ & $37 \pm 14.7$ & $4 \pm 2$ \\
\hline M3 & $24 \pm 5.35$ & $6.25 \pm 2$ & $64 \pm 12.4$ & $3 \pm 1.65$ \\
\hline
\end{tabular}

${ }^{a}$ Average \pm standard deviation.

(Fig. 2). The difference observed is consistent with DNA-DNA hybridization results since $S$. meliloti and genomic species 2 were found to exhibit 42 to $60 \%$ DNA homology (22). Thus, it can be deduced from these results that $S$. meliloti and genomic species 2 have diverged sufficiently to be considered two distinct species. Isolate A $321^{\mathrm{T}}$ and isolate $\mathrm{CC} 169$ belonging to group B of Eardly et al. (8) have identical 16S rRNA sequences between position 17 and position 276 (Fig. 1), a variable region in the ribosomal gene which allows $S$. meliloti and genomic species 2 to be distinguished. This finding confirmed that genomic species 2 and the group B strains of Eardly et al. (7) are equivalent, as noted previously $(3,22)$. A phylogenetic tree was constructed by transforming the $16 \mathrm{~S}$ rDNA sequence variations into evolutionary distance values (Fig. 2). Bradyrhizobium japonicum and Azorhizobium caulinodans were used as the outgroups. This analysis revealed the relationship between genomic species 2 and the Sinorhizobium species, as well as the relationship between the genus Sinorhizobium and the other genera of the Rhizobiaceae. The results of this phylogenetic analysis showed that genomic species 2 and $S$. meliloti are closely related taxa in the Sinorhizobium group and suggested that these two species diverged later than the other species of the genus. The genetic divergence is supported by the results of the numerical analysis of 63 auxanographic and biochemical characteristics (Fig. 3), which showed that S. meliloti and genomic species 2 have distinct phenotypic characteristics (Table 5).
Since annual Medicago species exhibited various sinorhizobial specificities $(2,3,21)$, we wondered if the symbiotic properties could be used to discriminate between $S$. meliloti and genomic species 2 . To examine this possibility, we chose a promiscuous nodulating plant species and a more selective nodulating plant species for inoculations (M. truncatula and $M$. polymorpha, respectively). All isolates of $S$. meliloti and genomic species 2 were able to nodulate and fix nitrogen with the promiscuous plant species, $M$. truncatula. Conversely, only genomic species 2 isolates could nodulate effectively and fix nitrogen with $M$. polymorpha, $S$. meliloti isolates formed ineffective rudimentary and white nodules on this plant. Similar inefficient nodules were also observed and described by Brockwell and Hely (2) and by Brunel et al. (3) with the same host plant species. In the present study we demonstrated that the formation of such nodules is triggered by isolates belonging to $S$. meliloti. Consequently, $S$. meliloti forms effective nodules with $M$. truncatula $(3,22), M$. sativa, $M$. minima, $M$. orbicularis, and $M$. rigidula (3), whereas strains belonging to genomic species 2 form effective nodules with $M$. polymorpha in addition to the other Medicago species listed above.

It has been recognized previously that the phylogenetic relationship of the nod genes $(\operatorname{nod} D 1, \operatorname{nod} D 2, \operatorname{nod} D 3, \operatorname{nod} A$, $n o d B$ ) matches the host spectrum of rhizobia and reflects the taxonomic divisions within the Leguminosae $(6,31)$. On the basis of PCR-RFLP results, it was demonstrated that genomic species 2 and $S$. meliloti strains have different nodD gene pat-

TABLE 5. Phenotypic characteristics that distinguish S. meliloti and genomic species 2 isolates

\begin{tabular}{|c|c|c|c|c|c|c|c|}
\hline \multirow{2}{*}{ Taxon } & \multicolumn{2}{|c|}{$\begin{array}{l}\text { Utilization of the following } \\
\text { compounds as sole carbon sources: }\end{array}$} & \multirow{2}{*}{$\begin{array}{l}\text { Growth in the } \\
\text { presence of } \\
3 \% \text { (wt/vol) } \\
\mathrm{NaCl}\end{array}$} & \multirow{2}{*}{$\begin{array}{l}\text { Growth at } \\
\text { pH } 4\end{array}$} & \multicolumn{2}{|c|}{ Intrinsic antibiotic resistance } & \multirow{2}{*}{$\begin{array}{l}\text { Effective nitrogen } \\
\text { fixation on } \\
M . \text { polymorpha }\end{array}$} \\
\hline & $\begin{array}{l}\text { Sorbose and } \\
\text { D-fucose }\end{array}$ & $\begin{array}{l}\text { D-Xylose, salicin, } \\
\text { and ribose }\end{array}$ & & & Neomycin & Chloramphenicol & \\
\hline S. meliloti ${ }^{a}$ & $+^{b}$ & + & + & + & $\mathrm{R}$ & $\mathrm{v}^{c}$ & - \\
\hline Genomic species $2^{d}$ & - & - & $\mathbf{v}$ & $\mathbf{v}$ & $\mathrm{S}$ & $\mathbf{R}$ & + \\
\hline
\end{tabular}

a S. meliloti RCR 2011 and sinorhizobia isolated from annual Medicago spp. (Table 1).

${ }^{b}+$, positive; - , negative; $v$, variable; $R$, resistant; $S$, susceptible.

The isolates obtained from annual Medicago spp. are resistant, and strain RCR 2011 is susceptible.

${ }^{d}$ See Table 1. 
TABLE 6. Summary of data from this study and four recent studies that included extensive characterization of sinorhizobia obtained from annual Medicago species

\begin{tabular}{|c|c|c|c|c|c|}
\hline \multirow{2}{*}{$\begin{array}{c}\text { Authors or } \\
\text { study }\end{array}$} & \multirow{2}{*}{ Reference } & \multirow{2}{*}{$\begin{array}{l}\text { No. of } \\
\text { isolates } \\
\text { used }\end{array}$} & \multirow{2}{*}{ Method used } & \multicolumn{2}{|c|}{ Group or results } \\
\hline & & & & Genomic species 1 & Genomic species 2 \\
\hline Eardley et al. & 7 & 232 & Isoenzymes & A1 & B \\
\hline Eardley et al. & 8 & 2 & Partial 16S rRNA sequencing & $\begin{array}{l}\text { Sequence identical to } S \text {. meliloti } \\
\text { sequence }\end{array}$ & New sequence (strain CC169) \\
\hline \multirow[t]{2}{*}{ Brunel et al. } & 3 & 43 & $\begin{array}{l}\text { PCR-RFLP: } 16 \mathrm{~S} \text { rRNA + } \\
\text { intergenic spacer }\end{array}$ & AI & AII \\
\hline & & & PCR-RFLP: nifD-K & BI & BII \\
\hline \multirow[t]{4}{*}{ Rome et al. } & 22 & 73 & $\begin{array}{l}\text { PCR-RFLP: 16S rRNA + } \\
\text { intergenic spacer }\end{array}$ & 1 & 2 \\
\hline & & & PCR-RFLP: nifD-K & 1 & 2 \\
\hline & & & PCR-RFLP: nodD1 and nodD2 & 1 & 2 \\
\hline & & & DNA-DNA hybridization & Genomic species 1 ( $S$. meliloti $)$ & Genomic species 2 \\
\hline \multirow{2}{*}{ This study } & & & Phenotypic tests & 1 & 2 \\
\hline & & & Total 16S rRNA sequencing & $\begin{array}{l}\text { Sequence identical to } S \text {. meliloti } \\
\text { sequence }\end{array}$ & $\begin{array}{l}\text { New sequence (strain A } \\
321^{\mathrm{T}} \text { ) }\end{array}$ \\
\hline
\end{tabular}

terns (22). In this study we found that genomic species 2 strains do not have the same host spectrum as $S$. meliloti strains. Consequently, it is possible that differences in nodD patterns may be related to an adaptation between genomic species 2 isolates and certain Medicago host plant species, such as $M$. polymorpha.

A summary of data from four recent studies, including the results of an extensive characterization of annual Medicago sinorhizobia, is shown in Table 6 . Common reference strains were included in all of these studies, which allowed comparisons to be made. The large number of strains studied, together with the wide range of geographical origins, allowed us to conclude that Sinorhizobium strains that nodulate Medicago species can be separated into two genetic groups on the basis of isoenzyme patterns (7), chromosomal and plasmid typing data (22), DNA-DNA hybridization data (22), phenotypic test data, symbiotic properties, and 16S rRNA sequence data and that these groups correspond to two species. Genomic species 1 corresponds to $S$. meliloti since strain RCR 2011, which belongs to this group, exhibited 73\% DNA-DNA homology with the $S$. meliloti type strain (strain ATCC 9930) (25). Moreover, strains RCR 2011 and ATCC $9930^{\mathrm{T}}$ had identical PCRRFLP 16S rDNA genotypes (18) and isoenzyme electrophoretic types (7). Since strain RCR 2011 is closely related to strain ATCC $9930^{\mathrm{T}}$, it is currently used as an $S$. meliloti reference strain $(3,5,7,18,22,25)$.

Genomic species 2 , which was clearly identified by all of the approaches described above (Table 6), is a new Sinorhizobium species, for which we propose the name Sinorhizobium medicae.

Description of Sinorhizobium medicae sp. nov. Sinorhizobium medicae (me'di.cae. N.L. gen. N. medicae, from medica, the Latin name for plants belonging to the genus Medicago). Gram-negative, aerobic, non-spore-forming rods. Colonies on YEM agar are circular, mucous, and semitranslucent and spread over an entire plate within 3 to 5 days at $28^{\circ} \mathrm{C}$. The mean generation times range from 3 to $5 \mathrm{~h}$ in YEM medium. The maximum temperature for growth is $40^{\circ} \mathrm{C}$ for most strains. Growth at $28^{\circ} \mathrm{C}$ on YEM agar is inhibited by $3 \%$ (wt/vol) $\mathrm{NaCl}$ and by $\mathrm{pH}$ values of less than 5.0. The strains are resistant to penicillin $\mathrm{G}$, nalidixic acid, chloramphenicol, and streptomycin and are able to use 25 of 49 carbohydrates tested. Strains belonging to this species have been isolated from $M$. truncatula (22), M. orbicularis (7), $M$. polymorpha $(3,7)$, and $M$. rugosa (8) from different geographical sites (south of France $[3,22]$ and eastern Mediterranean basin [7]) which are located in the center of origin of the genus Medicago. The strains are able to nodulate the Medicago species from which they were isolated. $S$. medicae can be distinguished from $S$. meliloti on the basis of its host spectrum since $S$. medicae strains fix nitrogen on $M$. polymorpha, whereas $S$. meliloti strains form ineffective nodules on $M$. polymorpha. $S$. medicae can be differentiated from the other members of the genus Sinorhizobium by phenotypic and genomic characteristics and particularly by its unique $16 \mathrm{~S}$ rRNA sequence. The type strain of $S$. medicae is strain A 321, which has the characteristics given above for the species.

\section{ACKNOWLEDGMENTS}

We thank Jaqueline Haurat and Lucette Mauré for their excellent technical assistance. We thank Benoit Cournoyer for helpful discussions and for a critical reading of the manuscript.

This research was supported by the Centre d'Analyse Moléculaire de la Biodiversité (University of Lyon, Lyon, France).

\section{REFERENCES}

1. Brenner, D. J., A. C. McWhorter, J. K. Leete Knutson, and A. G. Steigerwalt. 1982. Escherichia vulneris: a new species of Enterobacteriaceae associated with human wounds. J. Clin. Microbiol. 15:1133-1140.

2. Brockwell, J., and F. W. Hely, 1966. Symbiotic characteristics of Rhizobium meliloti: an appraisal of systematic treatment of nodulation and nitrogen fixation interaction between hosts and rhizobia of diverse origins. Aust. J. Agric. Res. 17:885-899.

3. Brunel, B., S. Rome, R. Ziani, and J. C. Cleyet-Marel. 1996. Comparison of nucleotide diversity and symbiotic properties of Rhizobium meliloti populations from annual species of Medicago. FEMS Microbiol. Ecol. 19:71-82.

4. Chen, W. X., G. H. Yan, and J. L. Li. 1988. Numerical taxonomic study of fast-growing soybean rhizobia and a proposal that Rhizobium fredii be assigned to Sinorhizobium gen. nov. Int. J. Syst. Bacteriol. 38:392-397.

5. De Lajudie, P., A. Willems, B. Pot, D. Dewettinck, G. Maestrojuan, M. Neyra, M. D. Collins, B. Dreyfus, K. Kersters, and M. Gillis. 1994. Polyphasic taxonomy of rhizobia: emendation of the genus Sinorhizobium and description of Sinorhizobium meliloti comb. nov., Sinorhizobium saheli sp. nov., and Sinorhizobium teranga sp. nov. Int. J. Syst. Bacteriol, 44:715-733.

6. Dobert, R. C., B. T. Breil, and E. W. Triplett. 1994. DNA sequence of the common nodulation genes of Bradyrhizobium elkanii and their phylogenetic relationships to those of other nodulating bacteria. Mol. Plant-Microbe Interact. 5:564-572.

7. Eardly, B. D., L. A. Materon, N. H. Smith, D. A. Johnson, M. D. Rumbaugh, and R. K. Selander. 1990. Genetic structure of natural populations of the nitrogen-fixing bacterium Rhizobium meliloti. Appl. Environ. Microbiol. 56: 187-194.

8. Eardly, B. D., J. P. W. Young, and R. K. Selander. 1992. Phylogenetic position of Rhizobium sp. strain Or191, a symbiont of both Medicago sativa and Phaseolus vulgaris, based on partial sequences of the 16S rRNA and nifH genes. Appl. Environ. Microbiol. 58:1809-1815.

9. Felsenstein, J. 1985. Confidence limits on phylogenies: an approach using 
the bootstrap. Evolution 39:783-791.

10. Fred, E. B., I. L. Baldwin, and E. McCoy. 1932. Root nodule bacteria and leguminous plants. University of Wisconsin Press, Madison.

11. Gibson, A. H. 1980. Methods for legumes in glasshouse and controlled environment cabinets, p. 139-184. In F. J. Bergersen (ed.), Methods for evaluating biological nitrogen fixation. John Wiley and Sons, New York.

12. Graham, P. H., M. J. Sadowsky, H. H. Keyser, Y. M. Barnet, R. S. Bradley, J. E. Cooper, D. J. De Ley, B. D. W. Jarvis, E. B. Roslycky, B. W. Strijdom, and J. P. W. Young. 1991. Proposed minimal standards for the description of new genera and species of root- and stem-nodulating bacteria. Int. J. Syst. Bacteriol. 41:582-587.

13. Higgins, D. G., and P. M. Sharp. 1988. Clustal: a package for performing multiple alignment on a microcomputer. Gene 73:237-244.

14. Hillis, D. M., and M. T. Dixon. 1991. Ribosomal DNA: molecular evolution and phylogenetic inference. Q. Rev. Biol. 4:411-453.

15. Jarvis, B. D. W, H. L. Downer, and J. P. W. Young. 1992. Phylogeny of fast-growing soybean-nodulating rhizobia supports synonymy of Sinorhizobium and Rhizobium and assignment to Rhizobium fredii. Int. J. Syst. Bacteriol. 42:93-96.

16. Jordan, D. C. 1984 . Rhizobiaceae Conn 1938 , 321 ${ }^{\mathrm{AL}}$, p. $234-256$. In N. R. Krieg and J. G. Holt (ed.), Bergey's manual of systematic bacteriology, vol. 1. The Williams \& Wilkins Co., Baltimore.

17. Kimura, M. 1980. A simple method for estimating evolutionary rates of base substitutions through comparative studies of nucleotide sequences. J. Mol. Evol. 16:111-120.

18. Laguerre, G., M. R. Allard, F. Revoy, and N. Amarger. 1994. Rapid identification of rhizobia by restriction fragment length polymorphism analysis of PCR-amplified 16S rRNA genes. Appl. Environ. Microbiol. 60:56-63.

19. Lesins, K., and I. Lesins. 1979. Genus Medicago (Leguminosae). A taxogenic study. Junk, The Hague, The Netherlands.

20. Mullis, K. B., and F. A. Faloona. 1987. Specific synthesis of DNA in vitro via a polymerase catalysed chain reaction. Methods Enzymol. 153:335-350.

21. Provorov, N. A. 1994. The interdependence between taxonomy of legumes and specificity of their interaction with rhizobia in relation to evolution of the symbiosis. Symbiosis 24:183-200.

22. Rome, S., B. Brunel, M. P. Fernandez, P. Normand, and J. C. Cleyet-Marel. 1996. Evidence of two genomic species of Rhizobium associated with Medicago truncatula revealed by PCR/RFLP and DNA/DNA hybridizations. Arch. Microbiol. 165:285-288.

23. Saitou, N., and M. Nei. 1987. A neighbor-joining method: a new method for reconstructing phylogenetic trees. Mol. Biol. Evol. 44:406-425.

24. Sanger, F., S. Nicklen, and A. R. Coulson. 1977. DNA sequencing with chain-terminating inhibitors. Proc. Natl. Acad. Sci. USA 74:5463-5467.

25. Scholla, M. H., J. A. Moorefield, and G. H. Elkan. 1990. DNA homology between species of rhizobia. Syst. Appl. Microbiol. 13:288-294.

26. Sneath, P. H. A., and R. R. Sokal. 1973. The principles and practice of numerical classification, p. 223-234. W. H. Freeman and Sons, San Francisco.

27. Vincent, J. M. 1970. A manual for the practical study of root nodule bacteria. IBP (Int. Biol. Programme) Handb. 15:3-4.

28. Weisburg, W. G., S. M. Barns, D. A. Pelletier, and D. J. Lane. 1991. 16S ribosomal DNA amplification for phylogenetic study. J. Bacteriol. 173:697703

29. Willems, A., and M. D. Collins. 1993. Phylogenetic analysis of rhizobia and agrobacteria based on 16S rRNA gene sequences. Int. J. Syst. Bacteriol. 43:305-313.

30. Yanagi, M., and K. Yamasato. 1993. Phylogenetic analysis of the family Rhizobiaceae and related bacteria by sequencing of 16S rRNA gene using PCR and DNA sequencer. FEMS Microbiol. Lett. 107:115-120.

31. Young, J. P. W., and A. W. B. Johnston. 1989. The evolution of specificity in the legume-Rhizobium symbiosis. Trends Evol. Ecol. 4:341-348. 